This item was submitted to Loughborough's Research Repository by the author.

Items in Figshare are protected by copyright, with all rights reserved, unless otherwise indicated.

\title{
When planned IS/IT project benefits are not realized: a study of inhibitors and facilitators to benefits realization
}

PLEASE CITE THE PUBLISHED VERSION

http://dx.doi.org/10.1016/j.jproman.2014.06.012

\section{PUBLISHER}

(C) Elsevier, APM and IPMA

\section{VERSION}

AM (Accepted Manuscript)

\section{PUBLISHER STATEMENT}

This work is made available according to the conditions of the Creative Commons Attribution-NonCommercialNoDerivatives 4.0 International (CC BY-NC-ND 4.0) licence. Full details of this licence are available at: https://creativecommons.org/licenses/by-nc-nd/4.0/

\section{LICENCE}

CC BY-NC-ND 4.0

\section{REPOSITORY RECORD}

Coombs, Crispin. 2019. "When Planned IS/IT Project Benefits Are Not Realized: A Study of Inhibitors and Facilitators to Benefits Realization”. figshare. https://hdl.handle.net/2134/15718. 
Research Article

WHEN PLANNED IS/IT PROJECT BENEFITS ARE NOT REALIZED: A STUDY OF

INHIBITORS AND FACILITATORS TO BENEFITS REALIZATION

Crispin R. Coombs

Centre for Information Management

School of Business and Economics, Loughborough University,

Ashby Road, Loughborough, LE11 3TU, UK

c.r.coombs@lboro.ac.uk

Running Title: When benefits are not realized

Corresponding author:

Dr Crispin Coombs

Senior Lecturer in Information Systems

Centre for Information Management

School of Business and Economics

Loughborough University,

Ashby Road, Loughborough, UK, LE11 3TU

c.r.coombs@lboro.ac.uk

+44(0)1509228835 


\title{
WHEN PLANNED IS/IT PROJECT BENEFITS ARE NOT REALIZED: A STUDY OF
}

\section{INHIBITORS AND FACILITATORS TO BENEFITS REALIZATION}

\begin{abstract}
$\underline{\text { Abstract }}$
IS/IT evaluations reveal that many organizations fail to realize planned benefits from their IS/IT projects. Benefits management researchers argue that organizational change is necessary for the delivery of IS/IT project benefits. However, existing IS/IT evaluation methods adopt a narrow quantitative focus on costs and benefits and fail to consider the organizational dimension. This study brings together the concepts of benefits management and IS/IT evaluation using the Cranfield Benefits Dependency Network (BDN) as a diagnostic tool to examine an under performing IS/IT project. The analysis revealed that planned benefits had not been realized because of a lack of attention to technical and organizational facilitators and inhibitors associated with IT-enabled organizational change.
\end{abstract}

Keywords:

Benefits management; benefits dependency network; information systems; evaluation 


\section{INTRODUCTION}

Information System and Information Technology (IS/IT) evaluations frequently reveal that organizations are failing to achieve the intended benefits from their IS/IT investments. For example, Barker and Frolick (2003) describe how a major soft drink bottler’s ERP system was intended to provide the benefit of integrated communication, but once live was considered a hindrance to the overall business. Similarly, Peppard et al., (2007) report the case of a new customer relationship management system that was delivered to time, budget and specification but provided no immediate benefits to the organization. These studies show that if investments in information systems and information technology are to be considered successful then they have to achieve more than technical targets such as satisfying a project's budget, time scale and feature requirements.

Firm-level economic studies have found that variation in the level of organizational change can explain the differential effects of computer use on productivity across organizations (Gregor et al., 2006). IT-related organizational transformation can engender changes in business processes and work practices that in turn reduce costs, increase output quality, enable new product development and improved customer service. All of these benefits form a significant component of the value of IS/IT investment (Brynjolfsson and Hitt, 2000). IS/IT benefits management (BM) studies draw similar conclusions. Ward and Peppard (2002) argue that although pre-investment appraisal and post-implementation review are important, they are insufficient to ensure the maximum benefits available are delivered. Marchand and Peppard (2008) argue that most benefits from IS/IT come from changes in the way an organization does business and not from the introduction of the new technology itself. Such benefits can range from providing 'problem-based solutions' to help achieve business objectives to 'innovation-based solutions', which allow organizations to exploit business opportunities or create new organizational competencies to achieve a competitive advantage 
(Peppard et al., 2007). However, the successful implementation of organizational change can present considerable challenges for projects. For example, it may be difficult to convince employees of the need for change, to agree a suitable strategy for the change process, to overcome resistance, and secure top management commitment for the proposed changes (Fernandez and Rainey, 2006). Therefore, it is important that managers understand the facilitators and inhibitors to the organizational transformation needed for the delivery of business-orientated benefits.

Unfortunately, this emphasis on organizational transformation is not reflected in IS/IT project evaluation methods, with many adopting a narrow quantitative focus on costs and benefits and treating evaluation as a technical problem (Stockdale and Standing, 2006). Common IS/IT appraisal techniques used by managers include return on investment, internal rate of return and net present value (Lin and Pervan, 2003). These techniques work on the premise that the cost of an investment is directly related to the benefits. However, the problem with this rationale is the significant gap between costs being incurred and the actual realization of benefits. During this time a range of organizational issues could influence the delivery of benefits, such as resistance to business process change, turnover of key stakeholders, or changes in power relationships (Love et al., 2005). This has led to calls for greater attention to contextual factors during evaluations (Schryen, 2013) more accurately representing the actuality of projects.

Hodgson and Cicmil (2006) observe that many project management researchers have also tended to focus on the frequency of use and which traditional project management practices and evaluation techniques should be applied, rather than what actually happens in projects. They suggest that this imbalance may reveal why the existing project management literature does not satisfactorily explain actuality in project environments. For example, these studies may not capture the complex relationships that occur between technologies, 
organizational changes and business benefits during projects. Consequently, Cicmil et al., (2006) call for more research that studies the ‘actuality’ of project-based working. They argue that such research may be better placed to reflect the complex social settings in which projects are undertaken and the means through which the relations between diverse participants and technologies are coordinated and controlled.

Against this background, the aim of the current study was to investigate the facilitators and inhibitors to IT-enabled organizational transformation required for benefits delivery. The study takes a socio-technical view of benefits realization that considers the human aspects to be as important, and closely entangled with, technical aspects (Orlikowski and Scott, 2008). The study was based on a single in-depth case study of a Financial Management System (FMS). As many IS/IT projects are completed but do not deliver their intended benefits, an under-performing FMS was chosen for investigation. It was envisaged that studying an under-performing case, rather than an outright failure, would provide rich data regarding both inhibitors and facilitators to benefits realization. The study comprised of two stages. Firstly, a post-hoc reinterpretation of business documents provided by the case study enabled the identification of planned changes and business benefits. Secondly, interviews were conducted with key informants to determine the extent to which planned changes and benefits had been actually realized and the facilitators and inhibitors to associated organizational change.

The study has theoretical significance because it has important implications for models of IS/IT evaluation, indicating that the study of relationships between technical functionality, organizational change and benefit realization are important dimensions to be included in evaluation frameworks. The study also has practical significance, demonstrating a diagnostic tool for existing IS/IT projects. Providing practitioners with a better understanding of the facilitators and inhibitors to organizational change and benefits realization increases 
the likelihood of successful remedial action and improves the likelihood of delivering value from operational systems.

The structure of this paper is as follows. The following section summarizes the relevant IS/IT evaluation and BM literature before presenting a critique to justify the research questions. The single case study research design and methods are then discussed. The following findings section compares the planned benefits, facilitators and inhibitors anticipated from the implementation of the system and the realized benefits, facilitators and inhibitors present once the system went live. The final section discusses the significance of the results and highlights issues for further research.

\section{LITERATURE REVIEW}

There has been a decline in the number of articles in the field of IS evaluation since 2000 (Schryen, 2013) and Frisk et al. (2014:2) state that 'there have been relatively few new ideas on evaluation methods put forward in the last two decades and almost none in recent years.' Much of the research that has been undertaken in this domain has been concerned with developing pre-implementation appraisal methods with which to evaluate IS/IT investments and frameworks classifying IS/IT value (Mohan et al., 2011). The primary focus of these methods has been improving investment decisions regarding IT projects leading to at least 30 different IS/IT evaluation methodologies available to practitioners (Andresen et al. 2000) By contrast, the literature around post-implementation evaluation is relatively sparse (Irani, 2010).

There appears to be consensus in the evaluation literature that post-implementation reviews are a valuable activity (Irani, 2010). However, the adoption of such reviews in practice remains low (Al-Yaseen et al. 2008). Those that are conducted tend to be highly static in nature and only represent the interests of one or two stakeholders. They often only 
receive management's attention for a short time span before being committed to corporate history, seldom to be used or reviewed again (Reymeni and Sherwood-Smith, 1998). Thus organizational learning opportunities to engineer out bad practice may be missed. Irani (2010) suggests that the low uptake may be due to managers holding the view that the IS/IT investment has been made and that there is little further that can be done if the investment was a mistake. Consequently, even when post-implementation evaluations are undertaken their value appears limited. This has led Irani (2010) to argue for a tighter linking between ex-ante and ex-post IS/IT evaluation through robust project management to improve the likelihood of achieving the original objectives of the investment. The effective management of tangible and intangible value generated from IS/IT investments is a core aspect of an independent discipline Ward et al., (1996) termed benefits management.

Benefits management $(\mathrm{BM})^{1}$ has been defined as 'the process of organizing and managing, such that the potential benefits arising from the use of IT are actually realized' (Ward and Elvin, 1999). BM has received increasing attention in recent years as a distinct area of academic study (Doherty et al., 2012). Breese (2012) observes that contributors to the BM debate vary and include practitioners (e.g. Thorp, 2001), consultants (e.g. Bradley, 2006; Jenner, 2009) and academics (e.g. Ashurst, 2012). However, despite this interest Doherty (2014) observes that BM as a discipline is still in its relative infancy with only a small number of models and tools to define its practice being produced. For example, the Model of Benefits Identification (MBI) (Changchit et al., 1998) the Active Benefit Realization Process (ABR) (Remenyi et al., 1997); and the Benefits Management Process Model (Ward and Daniel, 2006) have all been developed to increase the likelihood of benefits being delivered from IT projects. However, both the MBI and the ABR are conceptual models, the former

\footnotetext{
${ }^{1}$ In this paper the term benefits management (BM) refers to benefits management in the IS/IT context.
} 
developed from empirical data, and both models lack further empirical testing. The Benefits Management Process Model and its core tool, the Benefits Dependency Network has received the most empirical attention in the literature (e.g. Wilson et al., 2007; Rogers et al., 2008; King, 2011) but despite this interest the organizational uptake of this model still appears to be low (Ashurst et al., 2008).

More recently, BM has also been studied outside the IT/IS context at the programme management and portfolio level (Breese, 2012). Programme management concerns the management of a set of projects, which share a common objective, client or resources, while portfolio management considers the entire range of projects that an organization is involved with (De Reyck et al., 2005). Lycett et al., (2004) report that accepted practice such as Managing Successful Programs (MSP) recommends that BM should be conducted at the programme level arguing that project managers are not in the best position to consider the validity of their projects. Breese (2012) adds that portfolio management, combined with benefits realisation, can be considered as an additional stage to ensure that as well as executing projects to a high standard; the correct projects are selected for implementation. However, when investigating the actual practices used on programs in commercial and UK public sector organizations, Pellegrinelli et al., (2007) found that the application of BM to general project management situations was not being systematically or rigorously practiced, despite the availability of accepted practice guidance such as MSP. More recently, also in the wider project management field, Martinsuo (2013) found that decision making in portfolio management was less planned and rational than existing normative models would suggest. Thus, it appears that the adoption of BM practices remains low at the project, programme and portfolio levels, in both the IS/IT and general project management fields, and provides a further illustration of the all too common gap between theory and practice (Doherty et al., 2012). 
One of the defining principals of the BM approach is the instigation of an organizational change process that complements the new information system's functionality (Doherty, et al. 2012). As benefits are rarely generated solely from the introduction of a new technology it is vital that BM initiatives seek to transform the organization's structures and behavior to ensure a good fit between the host organization and the new IS/IT. Markus (2004) refers to these types of IT-enabled organizational change projects as a 'technochange' situation and differentiates them from both IT projects and organizational change projects. Markus argues that IT projects have a narrow focus, such as improving technical performance and reducing the costs of IS/IT ownership or maintenance, and organizational change projects tend to not have a strong IS/IT focus with more diffuse objectives such as enhancing organizational culture or effectiveness. By contrast, technochange projects use IS/IT in ways that can trigger major organizational changes, creating potentially high risk, high reward situations (Markus, 2004).

Organizations instigate technochange projects for two principal reasons. Either the desired organizational change cannot happen without IT, or the type of change required concerns major cross-functional re-design that does not work without an IT focus in many organizational cultures (Markus, 2004). This level of second-order or transformational change is likely to challenge shared assumptions and reframe the organizational system (Gareis, 2010). Such significant change is likely to cause widespread anxiety, confusion, business disruption, as well as temporary productivity loss (Cowan-Sahadath, 2010). However, the rewards are considerable with research demonstrating that the ability of the organization to change has a significant impact on the speed of return on IS/IT investments (Brynjolfsson and Hitt, 1998).

There are numerous studies presented in the organizational change management literature that identify various prerequisites required for successful change (Huy, 2001). 
These facilitators to organizational change include the project sponsorship role played by senior managers, changing attitudes and values of staff, selling the vision, implementing and sustaining the change (Kotter, 1996; Lacroix, 2001; Mento et al. 2002). Similar findings have been reported for IS/IT projects. For example, Fortune and White (2006) found the most common factors reported for IS/IT project success were the importance of a project receiving support from senior management; having clear and realistic objectives; and producing an efficient plan.

Countering the positive effects of these facilitators, the IS literature on critical success factors (CSF) has established that there are many aspects that may inhibit the successful completion of an IS/IT project. Several of these inhibitors represent the absence of facilitators identified in the change literature. For example, frequently mentioned inhibitors include a lack of top management support (Dong et al., 2009), negative user attitudes and a lack of user ownership (Authors, 2001) user resistance (Lapointe and Rivard, 2005) and a lack of attention to organizational issues (Doherty and King, 2005). However, despite these studies there is relatively little clear consensus in the IS literature concerning the key facilitators and inhibitors for successful IS/IT projects (Fortune and White, 2006). Further, change management skills among IT professionals still appear to be deficient, with many professionals lacking sufficient knowledge in the planning, execution and evaluation of change management (Pare and Jutras, 2004). Consequently, there is a pressing need for further research to examine the factors that influence the delivery of benefits from IT-enabled organizational change.

Petter at al., (2012) argue that bringing together streams of research on BM and IS/IT evaluation would be valuable to inform IS evaluation practice. Ward et al. (1996) suggest that BM techniques could be used to diagnose why some projects are successful in delivering benefits and others are not. However, Ashurst et al. (2008) report that although benefits are 
regularly considered during the development of a business case, once approval had been granted, the benefits focus rapidly disappears. As a result many IS/IT projects still end with the project being technically completed, but with the delivery of desired benefits lacking (Barker and Frolick, 2003; Peppard et al., 2007). Therefore, this study brings together the $\mathrm{BM}$ and IS/IT evaluation literature streams and utilizes an extended version of the Cranfield Benefits Dependency Network as a diagnostic tool to address the following research questions: 1) What are the facilitators and inhibitors to IT-enabled organizational transformation in an IS/IT project context? 2) How do facilitators and inhibitors to ITenabled organizational transformation influence the realization of business benefits from an IS/IT project? Figure 1 shows the research framework developed to guide the investigation. The following section explains the method adopted to investigate these research questions.

Insert Figure 1 here

\section{METHOD}

This study took a critical realist approach to address the research questions. Critical realism seeks to provide 'empirically supported statements about causation, specifically how and why phenomenon occurred' (Wynn and Williams, 2012: 789). This is consistent with the research questions for this study, and fits with calls from Cicmil et al., (2006) for more research on the actuality of IS/IT projects. Although Mingers et al. (2013) propose that critical realist studies should adopt mixed methods, Wynn and Williams (2012) suggest that the case study is the primary research design in this paradigm as it allows the in-depth study of the causal mechanisms in operation in specific contexts. According to Yin (2003) an exploratory case study design should be considered when a) the focus of the study is to answer 'how' and 'why' questions and b) the intervention being evaluated has no clear, 
single set of outcomes. This study fits with these criteria, as it did not propose a single set of inhibitors or facilitators or how those inhibitors/facilitators may influence the realization of business benefits. Darke et al. (1998) suggest single cases provide for in-depth investigation and rich description and can help to determine causalities between research constructs. Therefore, to gain the necessary in-depth interpretations surrounding the realization of benefits from an IS development project a single in-depth case study approach was adopted.

\section{$3.1 \quad \underline{\text { Research context }}$}

The UK public sector is one example of an organizational sector that has invested heavily in IS/IT but as yet has failed to reap the rewards anticipated (NAO, 2006). The findings of Doherty et al. (2012) suggest that the level of engagement and successful implementation of BM in the UK public sector remains mixed with many instances of underperforming systems. Consequently, a public sector organization (a finance department in a local government city council in England) was selected for the single in-depth case study.

The city council chosen as the case study site provided a large range of services from education to removing abandoned cars, monitoring air quality and the provision of cemeteries. In 2005, the council reviewed its legacy financial management system (FMS) and concluded that it was based on outdated technology with various functionality gaps. These gaps were overcome through a variety of additional databases, bolt-on software, or standalone systems. Continuing to maintain the legacy FMS was considered a barrier to the delivery of efficiencies and the implementation of new initiatives such as e-government. In February 2005 a business case was written to procure a new FMS for the council and was accepted in June 2005. The aim for the project was to develop new business processes, in parallel with the system implementation. Having approved the business case, the council decided to follow the PRINCE2 project management approach and a project initiation 
document was prepared and approved. A project board was assembled chaired by a senior responsible owner and comprising of key stakeholders in the project (e.g. Head of Finance, Strategic Director of Resources). Once the procurement process had been completed and the FMS supplier selected, project team training commenced, delivered by a consultant working on behalf of the FMS supplier. The FMS went live in April 2007 although some key functionality was not available until July 2009. However, by June 2010 anecdotal evidence suggested that the new FMS was not delivering the benefits that had been envisaged in the original business case. Although the FMS was live and supporting some business processes, employees reported that some legacy processes remained in place, not all employees were willing to use the new system, and there was limited confidence in data quality.

The FMS represented an underperforming or 'challenged' system, one that was not considered a complete failure, but also not a clear success (Yeo, 2002). Investigating an under performing system was considered an appropriate case for this study as it increased the likelihood of revealing the inhibitors to benefits delivery but also providing insights regarding facilitators to the benefits that had been achieved. Further, Rom and Rohde (2007) observe that research on management accounting and information systems has primarily relied on survey methods with few in-depth case studies undertaken. Therefore, adopting an in-depth case study approach provides a useful contribution to existing management accounting information system research, providing a deeper understanding of the complexity associated with a FMS project. Darke et al. (1998) suggest that data should be collected in a variety of ways for case study analysis. Consequently, our data collection strategy comprised of two stages that are explained in the following section. 


\subsection{Data collection}

The first stage of data collection was a retrospective detailed document review of sources written during the procurement and planning of the new FMS in 2005/2006. Sources included: the business case, project initiation document, project board and sub-group meeting minutes, cabinet reports and minutes, corporate strategy reports, risk analysis report and staff communication documents.

The second stage of data collection comprised of interviews with key informants. Newman (2005) advocates purposive selection when choosing participants for case study research to ensure the individuals selected will be particularly informative. The desired informant profile were individuals that would be able to give full and complete views regarding motivations for implementing the system, challenges associated with the project and perspectives on the outcomes of the operational FMS in terms of benefits achieved. Therefore, our sample included key informants, drawn from a range of organizational levels, either involved in the implementation of the FMS and/or were now users of the system as shown in Table 2. Interviewing informants from different organizational levels to ensured both strategic and operational perspectives were captured. The interviews were conducted over a four month period in 2011.

The main focus of the interviews was a retrospective exploration of realized benefits from the new FMS and the facilitators that led to benefits being achieved or the inhibitors that had prevented benefits realization. Table 1 presents the interview schedule that was used. The interviews were semi-structured to ensure each component of the benefits framework was discussed while still retaining the flexibility to explore emergent issues with key informants. Each interview was conducted, in-situ, at the site and the majority lasted more than an hour. To enhance the validity of the interview process, the informants were asked to supply specific 
evidence and examples to support their assertions. All the interviews were tape recorded and later transcribed verbatim.

\section{Insert Table 1 and Table 2 here}

\subsection{Data analysis}

To ensure a high focus on the key outcome of interest for this study, the realisation of business benefits from an IS/IT project, the benefits management literature was used to inform the data analysis strategy. After reviewing several alternative benefits management process models the Cranfield Benefits Management Process Model, and in particular its core tool, the Benefits Dependency Network (BDN), was chosen to guide the analysis. The Cranfield BDN has been advocated as an additional tool to improve the business case design for CRM projects (Wilson et al., 2007), engage sales force during new systems implementation (Rogers et al., 2008) and examine the contributions of organizational design and artifact engineering upon various stakeholders (King, 2011). The BDN highlights a number of broad constructs that are likely to influence the delivery of business benefits from an IS/IT investment (e.g. enabling changes, business changes).

However, while studies have demonstrated the value of the BDN for combining the technical and organizational perspectives (e.g. Ashurst et al., 2008; King 2011), it was primarily developed as a technique to help with the planning and management of benefits before and during IS/IT deployment. This planning and management emphasis may explain why some additional constructs, such as inhibitors to technical and/or organizational change are not included in the tool. Further, the BM literature provides little guidance on the precise constituents of the BDN constructs. For example, there is little direction on the type of 'business changes' required for benefit realization. Therefore, while the BDN provided a useful starting point we were careful to ensure that it did not constrain the data analysis to 
only considering the core original BDN constructs or how relationships between these constructs occurred. The Cranfield BDN is explained in more detail below.

The BDN is a framework that is designed 'to enable the investment objectives and their resulting benefits to be linked in a structured way to the business, organizational and IS/IT changes required to realize those benefits' (Ward and Daniel, 2006: 133). The network is created from right to left, with agreement on the investment objectives for the IS development project and identification of the expected business benefits associated with these objectives. Investment objectives are defined as organizational targets agreed for the investment and as a set describe what the situation should be on completion of the investment. By contrast, business benefits refer to an advantage on behalf of a particular stakeholder or group of stakeholders. Each benefit is then considered in turn and the changes necessary to realize the benefit are then identified. Two types of changes may be required. Business changes are permanent new ways of working that are required to ensure that the desired benefit is achieved and can be sustained. Enabling changes are prerequisites for achieving the business changes or may be essential to bring the system into effective operation within the organization. These enabling changes may only be required to be performed once and represent the facilitators needed to enact desired business change. Finally, the information technology or systems have to be considered. The required IS/IT enablers are identified to support the realization of anticipated benefits and allow the necessary changes to be undertaken. To reflect the focus of this study we relabeled 'enabling changes' as facilitators.

One feature of the BDN is that it gives no specific attention to inhibiting factors, compared to its focus on enabling and business changes (i.e. facilitators). This imbalance may be due to the frequent application of the $\mathrm{BDN}$ as a planning tool rather than as an evaluative tool. The IS literature has established that there are many factors that may inhibit the 
successful implementation of a new IS/IT investment. For example, frequently mentioned factors include a lack of top management support (Dong et al., 2009), user resistance (Lapointe and Rivard, 2005) and a lack of attention to organizational issues (Doherty and King, 2005). Therefore, we extended the standard BDN through the inclusion of an inhibitors construct.

The critical realist approach is associated with retroduction, a method 'to move from descriptions of empirical events or regularities to potential causal mechanisms, of a variety of kinds, some of which may be nonphysical and nonobservable, the interaction of which could potentially have generated the events' (Mingers et al., 2013: 797). Following this method, hypothetical mechanisms are proposed that, 'if they existed, would generate or cause that which is to be explained' (Mingers et al., 2013: 797). The generation of such hypotheses does not prove that the mechanisms do exist, and there may be competing explanations for the phenomenon. But these hypotheses do enable a focused investigation of interesting ideas, which may explain empirical events (Mingers et al., 2013). In this study it is proposed that facilitators/inhibitors to IT-enabled organizational change are casual mechanisms. In order to identify the facilitators and inhibitors to the organizational change enabled by the implementation of the FMS, as well as the business benefits realized from the FMS project, the data was coded using a table in a spreadsheet package. The data analysis described below was applied to stage one data (retrospective document review) and stage two data (interview transcripts and documents).

Using the BDN as a framework the analysis followed three concurrent activities identified by Miles and Huberman, (1994: 10) of data reduction, data display and conclusion drawing/verification. For stage one, data reduction involved reading documents such as the business case, project initiation document and risk analysis report to identify and code IS/IT enablers, facilitators, inhibitors, business changes, business benefits and investment 
objectives that had been planned for the FMS project. Categorizing the planned changes and business benefits required careful interpretation of the case study documentation especially when identifying investments objectives from business benefits. Targets for the FMS that were stated in general terms with no obvious association with a particular stakeholder or group of stakeholders were categorized as investment objectives e.g. the council wide standardization of processes. More specific advantages that could be associated with a particular stakeholder or group of stakeholders were categorized as business benefits e.g. improving the speed and accuracy of month-end and year-end reporting. However, although these advantages were labeled as benefits in the documentation from the case study site, the explicit association with particular stakeholders was rarely stated.

For stage two, data reduction involved reading all the interview transcripts several times to interpret and code informants’ perceptions of the business benefits that had been realized from the system. Informants were asked for examples of inhibitors, facilitators and business changes that they believed had contributed to either the delivery or prevention of benefits realization. The informants' claims were cross-referenced with the number of other participants that also made similar claims. The coding involved two steps. First, informants statements were matched to the definitions of the BDN constructs. Second, a code was applied that best described informants' views on the activities that occurred. Therefore, while the overall logic of the analysis was retroductive, it was operationalized through an initial deductive approach to identify the data that fitted with the definition of BDN constructs being examined, before a second inductive stage was used to determine labels derived from the data (Bryman, 2004).

The second phase of the data analysis involved data display using the BDN as a guide. Two data displays were created. The first matrix display represented the planned benefits, business change and anticipated facilitators and inhibitors to the FMS identified from the 
stage one (document) data, presented as Table 2 in the results section. The second display was constructed from stage two (interview) data in the form of an extended BDN to summarize the extent to which planned benefits had been realized, presented as Figure 2 in the results section. We considered using the case study’s pre-existing organizational performance measures to gauge the extent to which each activity mapped in the BDN had been achieved at the time of conducting the interviews. However, these measures were at a very high level and could be influenced by many non-IS/IT related factors. Therefore, they were not suitable to provide a direct objective measure for the performance of the FMS. Several studies have adopted perceptual measures for assessing value and performance from IS/IT (Jeffers et al. 2008; Nevo and Wade, 2010) and Tallon and Kraemer (2007) argue that perceptual measures are 'sufficiently accurate, credible, and unbiased as to constitute a viable approach to IT impact assessment'. Thus, in the absence of reliable objective measures, we adopted a perceptual based rating for each construct of the BDN. We used the frequency that informants identified particular constructs to develop a rating of low (1-4 informants), medium (5 - 8 informants) or high ( $9-13$ informants). These ratings were based on quotes and specific examples given by informants about certain constructs. To ensure that the ratings were accurate and that the BDN had high validity, constructs were only counted at the first point they were mentioned, so repetition by individual informants would not skew the ratings. The ratings were also based on multiple sources of evidence and utilized convergent lines of inquiry from two or more informants for each construct, adding more confidence to the rating level (Yin, 2003).

Once the second phase of data analysis was completed the final phase involved conclusion drawing/verification. The goal was to identify common, unique and causal features in the data that would present insights into why planned benefits were not realized. To facilitate this process, the literature was revisited to synthesize the findings with existing 
studies. This synthesis helped us develop our insights into the causal mechanisms that suggest why some planned benefits had not been achieved.

\section{$4 \quad \underline{\text { RESULTS }}$}

The following sections present the results of the case study analysis. The first section reports the planned benefits, facilitators and inhibitors identified for the FMS derived from the document review. The second section outlines the realized benefits, facilitators and inhibitors that were evident as reported by informants. The final section presents the BDN developed from the interview data to examine the gap between planned and realized benefits. The BDN also enabled an analysis of the relationships between facilitators and inhibitors of IT-enabled change and how these relationships influenced the realization of benefits.

\subsection{Findings from stage 1: Planned benefits}

Seven distinct business benefits were identified for the FMS shown in Table 3. These business benefits were described in the business case written in 2005. The benefits focused on efficiency gains and better decision-making but the definition of these benefits was imprecise. For example, ‘improvements' were expected in speed and accuracy of reporting and forecasting and control. However, the precise level of improvement was not specified. Other benefit descriptions were also vague. For example, 'the capture of meaningful information' was identified as a planned benefit in the business case, but the absence of an agreed definition of what constituted 'meaningful information' made assessment difficult.

Insert Table 3 
An additional type of planned benefit was a change in the role of human actors. It was envisaged accountants' roles would change, removing more routine tasks and facilitating the application of expert knowledge through ad hoc queries and monitoring. This change would create greater opportunities for accountants to identify opportunities for efficiency gains or cost savings, both contributing to the investment objective of reducing costs. It was recognized in the documentation that achieving this benefit would require a business change, namely the enactment of new monitoring routines and the abandonment of old processing activities. There was also recognition that some existing processes would require redesign although this business change was not directly related to any specific business benefits in the documentation.

Several one off planned facilitators were evident in the documentation. These changes addressed two aspects of system implementation: technical project related changes, such as training and having stable system; and more organizationally orientated changes such as changing the organizational culture and mapping and redesign of existing processes.

The risk analysis documentation indicated that relatively little consideration had been given to possible inhibitors to the delivery of planned benefits from the FMS. There was an acknowledgement that benefits may not be agreed or realized by departments, and that silo based working across other concurrent IS based projects could dilute overall benefit levels. Other concerns included the software supplier withdrawing product support for the legacy FMS and an over reliance on the new software supplier for consultancy and expertise. However, there was no reference to commonly encountered factors such as user resistance from business process change, or system quality issues. The risk analysis appeared to be mainly concerned with hazards associated with not implementing a new system or challenges of effectively managing the FMS project amongst the demands of other projects, rather than a 
full assessment of the possible technical and organizational risks of implementing the new FMS.

\subsection{Findings from stage 2: Realized Benefits from the FMS}

Table 4 shows three business benefits had been moderately achieved from the FMS by 2011, when the interviews were undertaken with informants. More relevant and reliable data was being captured from improved validation processes and the removal of duplicates and missing data. The data was more timely, being on average only 12 hours old, enabling quicker month end reporting and reductions in paper flow had also been achieved (see rows 1, 2 and 4 in Table 4 for supporting evidence).

Insert Table 4 here

However, realization of the other four planned benefits was low. Informants reported that there had been no improvement in the quality of forecasting and only minor improvements in control. The inconsistent adoption of ordering using the FMS also appears to have limited the level of control (see row 3 in Table 4). More efficient and consistent reporting to deliver timely management information was another planned benefit for the FMS that was rated as low realization. Informants reported the information was timelier but questioned whether it was effective due to the FMS enforcing strict data capture procedures that often required additional data entry. This additional work undermined the perceived benefit of timely information for some people. Informants also reported that the goal of improving the capture of meaningful data had not been realized. There appears to have been an aspiration that the data held on the FMS should be straightforward for non-finance specialists to understand. In terms of accountants acting as financial experts/advisors the 
overall benefit level was also low. The FMS had reduced some routine tasks for accountants and budget managers were now able to monitor their own budgets directly. However, these changes had not been achieved uniformly across the whole organization, which meant the role of accountants had not changed significantly (see row 6 in Table 4). It is interesting to note that achieving some benefits could undermine other benefits. For example, the strict validation controls in the FMS were seen as a benefit because they enforced more complete data capture that in turn reduced errors and enabled the system to provide more reliable data. However, the additional time required to follow the new procedures and constraints undermined the benefit of the system delivering timely management information.

\subsubsection{Facilitators}

The project had mixed success implementing facilitators as shown in the supporting

evidence in Table 5. Technically orientated facilitators such as training on using the FMS and the electronic processing of orders were moderately achieved. However, informants considered the FMS unstable. They reported that the web based browser regularly failed and that the data validation process caused the system to freeze, requiring a system restart and resulting in loss of data (see row 5 of Table 5).

Insert Table 5 here

When discussing more organizationally orientated facilitators such as the mapping and redesign of existing processes, informants reported that documenting current processes had been moderately achieved with some departmental participation. However, several informants felt there had been excessive focus on transactional processing and insufficient attention to new monitoring activities or to non-standard situations. Informants felt this 
deficiency could have been addressed had they been involved earlier in the project (see row 2 of Table 5). This lack of user engagement is likely to have been further compounded by the imposition of an electronic based way of working, without a structured effort to change the organizational culture of users. The supporting evidence in Table 5 suggests that the FMS was viewed as a technical change project rather than as a catalyst for organizational transformation.

\subsection{2 $\underline{\text { Inhibitors }}$}

Four inhibitors were identified from the interview data as shown in Table 6. Similar to facilitators, the inhibitors either related to organizational or technical issues. The most commonly identified organizational inhibitor related to staff not engaging with new ways of working engendered by the FMS. Budget managers and accountants generally showed a lack of interest in the new FMS and a reluctance to engage with the new opportunities it provided, preferring to maintain established routines. The standardization of practice that the FMS imposed was not reflected in managers’ existing practices and the requirement to align with the FMS was strongly resisted. This lack of consistency was also evident at a departmental level, reflected in the second organizational inhibitor of inconsistent departmental adoption of the FMS. As the quotes in rows one and two of Table 6 illustrate, the council departments did not operate consistent financial procedures with some departments choosing to maintain paper based activities, refusing to engage with electronic ordering, and even continuing to operate separate legacy systems. These quotes indicate that there were significant procedural and organizational issues within the council that inhibited the delivery of benefits from the FMS. 
Two technical inhibitors were also evident. These referred to the poor design of reports that were available from the FMS and slow system response times. The standard report outputs from the FMS were argued to not meet the needs of budget holders and accountants but may also be symptomatic of a desire to maintain existing practices. The slow system response times, especially when running queries and reports added frustration. Consequently, as well as being problems in their own right, these inhibitors compounded lack of engagement from individual managers and departments.

\subsubsection{Business changes}

Table 7 shows that the planned business change of workflow redesign to enable all orders /purchasing documentation to be approved and processed automatically had been moderately achieved. The ordering/purchasing process had been devolved to departments and was monitored and controlled using the new FMS. Orders could only be placed with approved suppliers registered on the system and paper order books had been removed across the organization. This business change has meant that the role of the user had changed to check system anomalies, or respond to specific triggers, rather than undertake the processing of orders or purchasing documentation.

Insert Table 7 here

By contrast, informants considered the planned business change of accountants and budget managers concentrating on more value adding activities to be less successful. For example, while the new FMS provided immediate access to information and budget managers were encouraged to take a more pro-active management approach utilizing bespoke reporting facilities, many budget managers did not embrace the new way of working and still asked 
operational staff to provide periodic standard budget reports. Some informants indicated that that this lack of engagement had prompted senior managers to apply control measures to attempt to change this behavior (see row 2 of Table 7 for supporting evidence). It appears that the council had more success when implementing prescriptive business changes, such as changes in transactional processing activities compared to business changes involving discretionary changes in the working practices of human actors.

\subsection{Analysis of relationships}

Having considered each of the constructs of the BDN this section considers the relationships identified between these constructs to explain why some planned benefits had not been achieved. The analysis revealed two patterns as shown in Figure 2. Firstly, the project had more success implementing the IS/IT modules and technically orientated facilitators and business changes. For example, a positive benefit path was created when the implementation of the accounts payable module (IS/IT enabler) enabled the pre-authorization of payments that were automatically matched to raised orders (facilitator). These changes required a change in business processes to accept electronic approvals rather than requiring paper based signatures (business change). The implementation of these changes contributed to the FMS providing more relevant and reliable data, improved reporting and reductions in the use of paper (business benefits) and improved performance against local and national performance indicators (investment objective). The complete realization of these benefits was moderated by the inconsistent adoption of the FMS across the council (inhibitor), which indicates that wider adoption of the system should further increase these benefits. However, it should be noted that the realization of these benefits did not require radical business process change. While the move to electronic signatures was significant in terms of financial control, once this decision had been agreed the associated procedural change was relatively low. 
However, the project encountered some difficulty implementing other technically orientated facilitators. For example, despite implementing all the FMS modules the system was not stable and frequently crashed. The slow response times (inhibitor) meant that more timely management information was not delivered and discouraged accountants from using the system to develop their role as experts and advisors (business benefit). The analysis also revealed that at least one enabling change was missed when the project was planned. The reported dissatisfaction with the standard reports from the FMS meant that the system failed to provide easy access to meaningful information. Therefore, it would appear that a redesign of these reports was necessary facilitator for this benefit to be realized.

The second pattern evident from Figure 2 is that the project encountered most difficulty when implementing organizationally orientated facilitators and business changes that required more radical organizational and behavioral adjustment. For example, while the mapping and redesign of business processes appears to have been moderately achieved (facilitator) it is only in respect to mapping existing procedures. Informants argued that no attention had been given to the redesign of new monitoring processes (business change) and change in the role of accountants and budget managers to more value-adding activities (such as ad-hoc monitoring) had not been achieved (business benefit). This lack of change was exacerbated by the absence of efforts to change the organizational culture of accountants. The low level of organizational transformation resulted in staff failing to embrace new ways of working (inhibitor) necessary for delivering the benefit of accountants changing their primary purpose from financial processing staff to experts/advisors.

\section{DISCUSSION AND CONCLUSIONS}

Existing IT/IS evaluation techniques lack sufficient focus on the role of organizational transformation for the realization of benefits. The BM literature considers organizational 
transformation but only through planning tools rather than evaluative techniques. This study addresses these gaps by examining the facilitators and inhibitors to IT-enabled organizational transformation and their influence on the delivery of benefits. This aim was operationalized through two research questions.

The first research question was to identify the facilitators and inhibitors to IT-enabled organizational transformation in an IS/IT project context. The results of the study demonstrated that, for this FMS project, facilitators and inhibitors could be divided into two main types: those that were technically orientated; and those that were organizationally orientated. Technical facilitators included training on the use of the FMS and the electronic processing of orders, whereas organizational facilitators included the mapping and redesign of existing processes and documenting existing processes. The study results indicate the organization had more success implementing technical facilitators, compared to organizational facilitators. This finding suggests the concerns raised by Pare and Jutras (2004) regarding a lack of change management skills among IT professionals remains a problem.

Regarding technical inhibitors, examples identified by participants included the poor design of reports produced by the FMS and low system performance in function response times. Organizational inhibitors included staff not engaging with new ways of working and inconsistent departmental adoption of the FMS across the organization. The key difference between these types of inhibitor is likely to be the ease by which they can be addressed. Assuming sufficient resources are available computer generated reports can be redesigned and increases in server or network capacity are relatively straightforward to implement. By contrast, persuading disaffected staff to adopt new ways of working and overcoming senior stakeholder resistance to departmental IT adoption may be considerably more challenging to achieve. Markus (2004) supports this view, suggesting that even in the absence of technical 
problems, organizational change efforts involving technology regularly fail because of negative reactions to changes in people's work, organizational business processes, and the technology they use.

The second research question investigated how the facilitators and inhibitors to ITenabled organizational transformation identified in this study influenced the realization of business benefits from the FMS project. The results suggest that for this case the level of facilitators and inhibitors did influence the level of IT-enabled organizational change achieved and the delivery of benefits. The analysis of relationships between facilitators, inhibitors and business change indicates that implementing facilitators such as training on the FMS and mapping of processes to at least moderate levels helped with achieving corresponding levels of business change and the delivery of benefits. The benefits were realized despite the presence of inhibitors, such as inconsistent adoption of the FMS. This may suggest that when broadly equal levels of facilitators and inhibitors are present, facilitators mitigate the negative influence of inhibitors. By contrast, some facilitators such as changes in organizational culture were at a low level, which appear to have contributed to the low level of associated business change, such as changes in the roles of accountants. In these instances, inhibitors such as staff not engaging with new ways of working were present at moderate or high levels. This finding suggests that not focusing on changing the organizational culture, a key facilitator, during the project meant these inhibitors were not sufficiently addressed. As a consequence, the associated planned benefits of ease of capture of meaningful information and accountants acting as financial experts were not realized.

As a result of investigating these research questions the study makes two important contributions. The first contribution is that it reinforces the view that IT-enabled organizational transformation is required in order to realize business benefits and investment objectives. In this case study, the introduction of a new FMS was treated largely as a 
technical change project rather than as an opportunity to transform business processes. Research has confirmed the importance of these non-technical aspects when considering IS/IT success (e.g. Authors et al. 2001; Gregor et al. 2006; Bradley et al. 2006). However, the extended BDN applied in this study goes further to reveal important relationships between technical functionality, facilitators, business changes and business benefits. For example, in this case, strategies to change the organizational culture of key stakeholders, and the development of new monitoring processes were lacking. The lack of attention to these facilitators explains why accountants and budget managers were not engaging with new value adding activities, such as running their own ad-hoc monitoring reports to pro-actively manage budgets and accounts. This lack of engagement inhibited the realization of the planned benefit of more efficient reporting and undermined the council's attempts to improve against local and national performance indicators, a key investment objective set for the new system.

This type of insight is missing in existing IT/IS investment evaluation tools. For example, applying the ABR model (Remenyi et al. 1997) or tools such as the internal rate of return (IRR) would provide a useful assessment of the current state of technical functionality implemented and level of benefits realized. However, they would not capture the level of organizational transformation that had been attempted, the specific type of organizational change adopted, or the nature and level of business change resistance that had been encountered. Consequently, this study has demonstrated the importance of examining both the degree of organizational transformation and the relationships between facilitators, inhibitors, organizational change and business benefits when conducting post-implementation IS/IT evaluations. These findings illustrate the complex nature of evaluating IS/IT investments and provide some empirical support for recent calls to consider multiperspective, multi-criteria and multi-stakeholder perspectives when trying to develop a full 
understanding of the interconnected nature of project performance (Schryen, 2013; Frisk et al. 2014).

The second contribution of this study is that it provided the opportunity to critique the BDN as a tool for reviewing IS/IT project implementations. The results demonstrated that several inhibitors such as individuals not engaging with new ways of working, and poor report design and system performance could reduce the level of planned benefit realization from the system. Therefore, extending the original BDN to include inhibitors is an important refinement necessary for the effective application of the BDN as a diagnostic tool. However, there are additional enhancements that could further improve the BDN. In particular, the core constructs of the BDN refer to high-level broad concepts that can potentially encapsulate a number of different elements. For example, the distinction between facilitators and business changes would benefit from further refinement with a closer examination of different types of change in both categories and possible interrelationships. Doherty et al. (2012) have shown that benefits realization can be enhanced through the consideration of traditional systems success factors. Therefore, the application of the IS/IT CSF studies may provide a potentially fruitful approach to address this deficiency, through examining which CSFs fit with the BDN constructs, and how relationships between CSF sub-constructs occur.

This study also has significance for IS/IT practitioners. Applying the enhanced BDN as a diagnostic tool provides a visual representation of causal relationships and clarity regarding specific areas requiring remedial attention from the IT practitioner. For example, in this study the enhanced BDN highlights the need for the council to address the inhibitors of departmental and individual resistance and low system performance levels and through revisiting the facilitators concerning organizational culture and improving the stability of the FMS. At the time of writing the council had instigated a number of actions in this respect. A change manager had been appointed to address the lack of attention given to organizational 
transformation and working groups had been established to enable stakeholders to influence the re-design of the reporting capabilities of the FMS. Thus, this study provides an illustration of how the BDN can be used as a complementary tool to link pre-investment appraisal with post implementation review to assess and explain the realization of benefits from an IS/IT investment (Irani, 2010).

While the study has provided some important new insights it is subject to a number of limitations. The investigation adopted a single in-depth case study approach. Consequently, the findings are limited in terms of their generalizibility. However, the standard nature of the type of IS/IT project chosen for study may increase the transferability of the results to other organizations. Further, the BDN has been applied in a number of different contexts for differing types of information system in previous research indicating that it may have value across various industries and systems as a diagnostic tool. The selection of a relatively small number of stakeholders at the case study site is also the source of potential bias. However, the informants were drawn from a range of different organizational sections at varying levels of seniority and the variations in opinion recorded from the different informants provided a strong indication that the results were not unduly biased. Consequently, although the study provides many interesting and novel insights, the aforementioned limitations should be taken into account when interpreting the results. Although the results of this study have been presented back to the case study site, it is not yet clear how successful suggested remedial actions have been in turning around the performance of the FMS. Of particular importance therefore, in terms of follow-up research, will be longitudinal studies to assess the progress of benefits realization, and assess the utility of the BDN. Further, the limitations also highlight the need for follow up studies, employing different methods such as survey techniques, targeting different organizations and industry sectors populations, to assess the full extent of the generalisibility of this study's findings. 
Al-Yaseen H., Eldabi T., Paul R.J. El-Haddadeh, R. 2008. Post- implementation evaluation of IT systems: A close review of politics. In: Irani Z and Love PED (eds). Evaluating Information Systems: Public and Private Sector. 1st edn, Chapter 7, ButterworthHeinemann: London, pp 134-152.

Andresen, J., Baldwin, A., Betts, M., Carter, C., Hamilton, A., Stokes, E. Thorpe, T. 2000. A framework for measuring IT innovation benefits, Electronic Journal of Information Technology in Construction 5, 57-72.

Ashurst C. 2012. Benefits Realization from Information Technology. Basingstoke, UK: Palgrave Macmillan.

Ashurst, C. Doherty NF., Peppard, J. 2008. Improving the impact of IT development projects: The benefits realization capability model, European Journal of Information Systems 17(4), 352-370.

Authors 2001. to be added after reviewing process

Barker, T. Frolick, MN. 2003. ERP implementation failure: a case study, Information Systems Management 20(4), 43-49.

Bradley, G., 2006. Benefit Realisation Management. Gower, Aldershot.

Bradley, RV. Pridmore, JL., Byrd, TA. 2006. Information systems success in the context of different corporate cultural types: An empirical investigation, Journal of Management Information Systems 23(2), 267-294.

Breese, R. 2012. Benefits realisation management: panacea or false dawn? International Journal of Project Management, 30 (3), 341-351.

Bryman, A., 2004. Social Research Methods, 2nd Edition. Oxford University Press, Oxford.

Brynjolfsson, E. Hitt, LM. 1998. Beyond the productivity paradox, Communications of the ACM 41(8), 49-55.

Brynjolfsson, E. Hitt, LM. 2000. Beyond computation: Information technology, organizational transformation and business performance, Journal of Economic Perspectives 14(4), 23-48.

Changchit, C., Joshi, KD. Lederer, AL. 1998. Process and reality in information systems benefit analysis, Information Systems Journal 8(2), 145-162.

Cicmil, S., Williams, T., Thomas, J., Hodgson, D., 2006. Rethinking Project Management: Researching the actuality of projects. International Journal of Project Management, 24, 675-686.

Coombs, C.R., Doherty, N.F., Loan Clarke, J., 2001. The importance of user ownership and positive user attitudes in the successful adoption of community information systems. Journal of End User Computing. 13 (4), 5-16.

Cowan-Sahadath, K. 2010 Business transformation: Leadership, integration and innovation A case study, International Journal of Project Management 28, 395-404.

Darke, P. Shanks, G. Broadbent, M. 1998. Successfully completing case study research: combining rigour, relevance and pragmatism, Information Systems Journal 7(2), 273290.

De Reyck, B., Grushka-Cockayne, Y., Lockett, M., Calderini, S.R., Moura, M. Sloper, A., 2005. The impact of project portfolio management on information technology projects. International Journal of Project Management 23 (7), 524-537.

Doherty, N.F. 2014. The role of socio-technical principles in leveraging meaningful benefits from IT investments, Applied Ergonomics, 45(2), 181-187.

Doherty, NF., King, M. 2005. From technical to socio-technical change: Tackling the human and organizational aspects of systems development projects, European Journal of Information Systems 14(1), 1-5. 
Doherty, NF., Ashurst, C. Peppard, J. 2012. Factors affecting the successful realization of benefits from systems development projects: findings from three case studies, Journal of Information Technology 27, 1-16.

Dong, L., Neufeld, D., Higgins, C. 2009. Top management support of enterprise systems implementations, Journal of Information Technology 24, 55-80.

Fernandez, S. and H.G. Rainey. 2006. Managing Successful Organizational Change in the Public Sector: An Agenda for Research and Practice, Public Administration Review, 66, 168-176.

Fortune, J. White, D. 2006. Framing of project critical success factors by a systems model. International Journal of Project Management, 24(1), 53-65.

Frisk, E.J., Bannister, F., Lindgren, R. 2014. Evaluation of information system investments: a value dials approach to closing the theory-practice gap. Journal of Information Technology, advance online publication: 1-17.

Gareis, R. 2010 Changes of organizations by projects, International Journal of Project Management, 28(4), 314-327

Gregor, S., Martin, M., Fernandez, W., Stern, S. Vitale, M. 2006. The transformational dimension in the realization of business value from information technology, Journal of Strategic Information Systems 15, 249-270.

Hodgson, D., Cicmil, S., 2006. Making Projects Critical. Palgrave Macmillan, Basingstoke.

Huy, Q.N., 2001. Time, temporal capability, and planned change. Academy of Management Review 4, 601-623.

Irani, Z. 2010. Investment evaluation within project management: an information systems perspective. Journal of the Operational Research Society, 61(6), 917-928.

Jeffers, P.I., Muhanna, W.A. Nault, B.R. 2008. Information technology and process performance: an empirical investigation of the interaction between IT and non-IT resources, Decision Sciences 39(4), 703-735.

Jenner, S., 2009. Realising Benefits from Government ICT Investment-A Fool's Errand? Academic Publishing, Reading.

King, N. 2011. A benefits dependency network as the bridge between requirements and business objectives: an ODE perspective, International Journal of Organisational Design and Engineering 1(3), 185-208.

Kotter, J.P., 1996. Leading the Change. Harvard Business School Press, Boston, MA. Lacroix.

Lacroix, J.J., 2001. Project change management. Project Management Journal, March. Vol. 32(1).

Lapointe, L. Rivard, S. 2005. A multiple model of resistance to information technology implementation, MIS Quarterly 29(3), 461-491.

Lin, C. Pervan, G. 2003. The practice of IS/IT benefits management in large Australian organizations, Information \& Management 41,13-24.

Love, PED., Irani, Z., Standing, C., Lin, C. Burn, JM. 2005. The enigma of evaluation: benefits, costs and risks of IT in Australian small-medium-sized enterprises, Information \& Management 42, 947-964.

Lycett, M., Rassau, A., Danson, J., 2004. Programme management: a critical review. International Journal of Project Management 22, 289-299.

Marchand, DA. Peppard, J. 2008. Designed To Fail: Why IT Projects Underachieve and What To Do About It. Cranfield School of Management: Cranfield.

Markus, M.L., 2004. Techno-change management: using IT to drive organizational change. Journal of Information Technology 19 (1), 4-20.

Martinsuo, M. 2013. Project portfolio management in practice and in context, International Journal of Project Management 31, 794-803. 
Mento, A.J., Jones, R.M., Dirndorfer, W., 2002. A change management process: grounded in both theory and practice. Journal of Change Management 3 (1), 45-59.

Miles, MB. Huberman, AM. 1994.. Qualitative Data Analysis: An Expanded Sourcebook, 2nd Edn. Sage Publications: London.

Mingers, J., Mutch, A., Willcocks, L., 2013. Critical realism in information systems research. MIS Quarterly 37(3), p.795-802.

Mohan, K., Ahlemann, F. Braun, J. 2011. Preparing for the future of IT project value realisation: understanding benefits management practices - do incentives and management support really help? in Proceedings of the Nineteenth European Conference on Information Systems, (Helsinki, Finland, 2011); Paper 16.

National Audit Office 2006. Delivering successful IT-enabled business change. Report by the Comptroller and Auditor General, HC 33-1, Session 2006 -2007, November.

Nevo, S. Wade, M.R. 2010. The formation and value of IT-enabled resources: antecedents and consequences of synergistic relationships, MIS Quarterly 34(1), 163-183.

Newman, WL. 2005. Social Research Methods 6th Edn. Pearson: London.

Orlikowski, W., Scott, S., 2008. Sociomateriality: Challenging the separation of technology, work and organization. Academy of Management Annals 2(1), 433-474.

Paré, G. Jutras, J-F. 2004. How good is the IT professional's aptitude in the conceptual understanding of change management? Communications of AIS (14), 653-677.

Pellegrinelli, S., Partington, D., Hemingway, C., Mohdzain, Z., Shah, M., 2007. The importance of context in programme management: an empirical review of programme practices. International Journal of Project Management 25, 41-55.

Peppard, J., Ward, J. Daniel, E. 2007. Managing the realization of business benefits from IT investments, MIS Quarterly Executive 6, 1-11.

Petter, S., DeLone, W. McLean, ER. 2012. The past, present, and future of "IS success", Journal of the Association for Information Systems, 13, 341-362.

Remenyi, D., Sherwood-Smith, M. and White, T. 1997. Achieving Maximum Value from Information Systems - A Process Approach, John Wiley, Chichester.

Reymeni, D. Sherwood-Smith, M. 1998. Business benefits from information systems through an active benefits realisation programme, International Journal of Project Management 16(2),81-91.

Rogers, B., Stone, M. Foss, B. 2008. Integrating the value of salespeople and systems: Adapting the benefits dependency network, Database Marketing \& Customer Strategy Management 15(4), 221-232.

Rom A, Rohde C. 2007. Management accounting and integrated information systems: a literature review. International Journal of Accounting Information Systems 8(1) 4068.

Schryen, G. 2013. Revisiting IS business value research: what we already know, what we still need to know, and how we can get there. European Journal of Information Systems, 22(2), 139-169.

Stockdale, R. Standing C. 2006. An interpretive approach to evaluating information systems: A content, context, process framework, European Journal of Operational Research 173, 1090-1102.

Tallon, P.P. Kraemer, K.L. 2007. Fact or fiction? A sense making perspective on the reality behind executives' perceptions of IT business value, Journal of Management Information Systems 24(1), 13-54.

Thorp, J., 2001. The Information Paradox: Realizing the Business Benefits of Information Technology. McGraw-Hill Ryerson, Toronto.

Ward, J. Daniel, E. 2006. Benefits Management: Delivering Value from IS and IT Investments, John Wiley and Sons, Chichester. 
Ward, J. Elvin, R. 1999. A new framework for managing IT-enabled business change, Information Systems Journal 9(3), 197-222.

Ward, J. Peppard, J. 2002. Strategic Planning for Information Systems, $3^{\text {rd }}$ Ed. John Wiley and Sons Ltd: Chichester.

Ward, J., Taylor, P. Bond, P. 1996. Evaluation and the realisation of IS/IT benefits, European Journal of Information Systems 4, 214-225.

Wilson, H., Clark, M. Smith, B. 2007. Justifying CRM projects in a business-to-business context: The potential of the Benefits Dependency Network, Industrial Marketing Management 36, 770-783.

Wynn, D., Williams, C.K., 2012. Principles for conducting critical realist case study research in information systems. MIS Quarterly 36(3), 787-810.

Yeo, KT. 2002. Critical failure factors in information system projects. International Journal of Project Management, 20(3), 241-246.

Yin, RK. 2003. Case Study Research. Sage Publications, Thousand Oaks.

\section{$7 \quad$ ACKNOWLEDGEMENTS}

I thank Mazer Hussain for his help with data collection. I also thank the three anonymous reviewers who provided many valuable comments that helped to improve the paper. 
Table 1 Interview Schedule

Question \# Topic

IS/IT Enablers

1 Which modules of the FMS have you or do you use?

2 Are you aware of any issues/problems encountered in getting any of the modules up and running?

Facilitators

3 What training was done for each module of the FMS?

4 What efforts were made to change the organizational culture?

5 How did you feel about the new system?

6 Were all existing processes mapped?

7 Were future/proposed processes mapped?

Business Changes

8 What changes have there been to:
a. Roles and responsibilities of Accountants and Budget Managers?
b. Payments process
c. Invoicing process
d. Purchasing
e. Planning
f. Budgeting

Business Benefits/Inhibitors*

9 Do you think the system produced more relevant and reliable data? If not why not?

10 Do you think the system has helped with the ease of capture of meaningful information? If not why not?

11 Do you think the system has improved the speed and accuracy of both month- end and year-end? If not why not?

12 Do you think the system has improved forecasting and control? If not why not?

13 Do you think the system has provided effective and timely management information? If not why not?

14 Do you think the system has minimized the time spent on processing? If not why not?

15 Do you think the system has reduced the use of paper? If not why not?

16 Do you think the system is user-friendly and intuitive? If not why not?

Investment Objectives

17 Do you think having the new system has achieved:
a. Increase system availability?
b. Reduce costs?
c. Minimize Errors and optimize links and integration between key systems?
d. Reduce Turnaround time of deliverables
e. Improve Performance against National/Local PI's?
f. Complete council-wide vision or standards for processes?

*Inhibitors were identified through follow up questions to participants to elicit what they had thought had prevented the delivery of particular business benefits. General note: For each question informants were asked to identify specific examples to support their opinions and additional probing questions were also asked as required to fully explore informant perceptions and ensure validity. 
Table 2 Details of Informants

\begin{tabular}{|c|c|c|c|}
\hline Name & & Role & Duration \\
\hline Accounts Clerk & $\# 1$ & I procurement user/AP user/discoverer viewer user & 40 mins \\
\hline $\begin{array}{l}\text { Accounts Payable (AP) } \\
\text { Supervisor }\end{array}$ & $\# 2$ & AP user group member/AR user/discoverer viewer user & 55 mins \\
\hline $\begin{array}{l}\text { Accounts Receivable } \\
\text { (AR) Supervisor }\end{array}$ & \#3 & AR user group member/AR user/discoverer viewer user & 70 mins \\
\hline Budget Manager & $\# 4$ & General Ledger user/discoverer viewer user & 45 mins \\
\hline $\begin{array}{l}\text { Business Systems } \\
\text { Accountant }\end{array}$ & \#5 & $\begin{array}{l}\text { Implementation team/reporting sub group chair/FMS } \\
\text { administrator/discoverer viewer and desktop user }\end{array}$ & 65 mins \\
\hline $\begin{array}{l}\text { Business Systems } \\
\text { Officer }\end{array}$ & \#6 & $\begin{array}{l}\text { Implementation team/trainer/FMS } \\
\text { administrator/discoverer viewer and desktop user }\end{array}$ & 75 mins \\
\hline $\begin{array}{l}\text { Business Systems } \\
\text { Manager }\end{array}$ & \#7 & The implementation team & 50 mins \\
\hline Group Accountant 1 & $\# 8$ & $\begin{array}{l}\text { APIG group member/General Ledger user/discoverer } \\
\text { viewer an desktop user }\end{array}$ & 75 mins \\
\hline Group Accountant 2 & $\# 9$ & $\begin{array}{l}\text { APIG Group member/ General Ledger user and discoverer } \\
\text { viewer }\end{array}$ & 80 mins \\
\hline Head Of Finance & $\# 10$ & APIG Group chair/FMS board/discoverer viewer user & 55 mins \\
\hline Principal Accountant 1 & $\# 11$ & $\begin{array}{l}\text { Reporting sub group member/ General Ledger } \\
\text { user/discoverer viewer and desktop user }\end{array}$ & 70 mins \\
\hline Principal Accountant 2 & $\# 12$ & $\begin{array}{l}\text { General Ledger user/AP and AR inquiry user and } \\
\text { discoverer viewer }\end{array}$ & 80 mins \\
\hline $\begin{array}{l}\text { Strategic Director Of } \\
\text { Resources }\end{array}$ & $\# 13$ & Project sponsor/chair of FMS board & 50 mins \\
\hline
\end{tabular}


Table 3 Planned Benefits, Business Change and Anticipated Facilitators and Inhibitors to the FMS

\begin{tabular}{|c|c|c|c|c|c|}
\hline IT/IS Enablers & Facilitators & Business Changes & Inhibitors & Business Benefits & $\begin{array}{l}\text { Investment } \\
\text { Objectives }\end{array}$ \\
\hline Accounts Receivable & $\begin{array}{l}\text { Invoices to be processed } \\
\text { and dispatched } \\
\text { electronically }\end{array}$ & $\begin{array}{l}\text { Changes in the role of } \\
\text { accountants and budget } \\
\text { managers to more value } \\
\text { adding activities }\end{array}$ & $\begin{array}{l}\text { Over reliance on new } \\
\text { software company for } \\
\text { consultancy and expertise }\end{array}$ & $\begin{array}{l}\text { Improve the speed and } \\
\text { accuracy of both month- } \\
\text { end and year-end } \\
\text { reporting }\end{array}$ & $\begin{array}{l}\text { Adopt consistent } \\
\text { Council-wide } \\
\text { processing standards }\end{array}$ \\
\hline $\begin{array}{l}\text { Procurement/ } \\
\text { Commitment } \\
\text { Accounting }\end{array}$ & Training in FMS & & $\begin{array}{l}\text { Silo-based working in this } \\
\text { and other related projects } \\
\text { could dilute overall } \\
\text { benefits and produce } \\
\text { disappointing results }\end{array}$ & $\begin{array}{l}\text { More efficient and } \\
\text { consistent reporting } \\
\text { providing accurate, } \\
\text { effective and timely } \\
\text { management } \\
\text { information }\end{array}$ & Reduce costs \\
\hline \multirow{2}{*}{ Reporting } & $\begin{array}{l}\text { Establish stable platform } \\
\text { for FMS }\end{array}$ & & & $\begin{array}{l}\text { Ease of capture of } \\
\text { meaningful information }\end{array}$ & \\
\hline & & & & $\begin{array}{l}\text { Accountants to act as } \\
\text { financial experts } \\
\text { /advisors }\end{array}$ & \\
\hline
\end{tabular}


Table 4: Empirical Evidence for Realized Benefits

\begin{tabular}{|c|c|c|}
\hline $\begin{array}{l}\text { Planned Business } \\
\text { Benefit }\end{array}$ & Supporting evidence & Rating \\
\hline $\begin{array}{l}\text { Reduce paper } \\
\text { through automating } \\
\text { tasks e.g. web } \\
\text { based purchasing, } \\
\text { electronic orders } \\
\text { and invoices }\end{array}$ & $\begin{array}{l}\text { 'No paper orders, not posting mail and are emailed where possible, } \\
\text { no copies on file, all held electronically, no coding slips.' Budget } \\
\text { Manager (\#4) } \\
\text { 'Reduction in paper orders as no order books, these are emailed } \\
\text { where possible and mailed where not, theoretically no copies on file } \\
\text { and all held electronically, no coding slips. Things get scanned and } \\
\text { there is no need for paper to float around and you can look in the } \\
\text { system. ' Accounts Clerk (\#1) }\end{array}$ & Moderate \\
\hline $\begin{array}{l}\text { Improve the speed } \\
\text { and accuracy of } \\
\text { both month-end } \\
\text { and year-end } \\
\text { reporting }\end{array}$ & $\begin{array}{l}\text { 'Accuracy is still reliant on the information getting in, still reliant on } \\
\text { accountants processing recharges for information to be up to date } \\
\text { and accurate. It is better than before because reports can be set, } \\
\text { manual tasks can now be done accurately inputting orders and } \\
\text { matching to invoices.' AP supervisor (\#2) } \\
\text { 'Speed, yes, [...] reporting of both summary position and analysis } \\
\text { can be done a lot quicker now than previously.' Head of Finance } \\
\text { (\#10) }\end{array}$ & Moderate \\
\hline $\begin{array}{l}\text { Improved } \\
\text { forecasting and } \\
\text { control }\end{array}$ & $\begin{array}{l}\text { 'No [improvements] to forecasting but that's not the systems fault } \\
\text { that's the users fault for not using the system as intended again on the } \\
\text { ordering side'. Business Systems Manager (\#7) } \\
\text { 'If everybody ordered through [the FMS] there would be huge } \\
\text { increase in the control of the budgets. Because of commitment issues } \\
\text { we do a lot of it manually like we did before, forecasting and control } \\
\text { come down to discussions between the accountants/budget managers. } \\
\text { Head of Finance (\#10) }\end{array}$ & Low \\
\hline $\begin{array}{l}\text { More relevant and } \\
\text { reliable data }\end{array}$ & $\begin{array}{l}\text { 'Because of the rigid nature of [the FMS] it forces certain } \\
\text { information in and validates the entry therefore reducing the number } \\
\text { of errors that could occur.' Business Systems Accountant (\#5) } \\
\text { 'The system throws out errors, duplicate numbers, invalid CIS. There } \\
\text { are mandatory fields. Because the goods/services are linked to } \\
\text { [procurement module] it should pick up the correct supplier. You } \\
\text { can't pay the wrong supplier.' Group Accountant } 1 \text { (\#8) }\end{array}$ & Moderate \\
\hline $\begin{array}{l}\text { More efficient and } \\
\text { consistent } \\
\text { reporting }\end{array}$ & $\begin{array}{l}\text { 'The [process] has been improved but the processing mechanics } \\
\text { have been extended.' Accounts Clerk (\#1) } \\
\text { 'My gut feeling is it takes longer, it feels like you're wasting time.' } \\
\text { Principal Accountant } 1 \text { (\#11) }\end{array}$ & Low \\
\hline $\begin{array}{l}\text { Accountants to act } \\
\text { as financial experts } \\
\text { /advisors }\end{array}$ & $\begin{array}{l}\text { 'I don't think all budget managers have embraced the new system, } \\
\text { partly because other staff have done it [reporting] for them'. } \\
\text { Business Systems Officer (\#6) } \\
\text { 'Some budget managers run reports others don't. Some people input } \\
\text { and raise orders in [the FMS], others still make notes and paper is } \\
\text { used and then input by another.' Business Systems Manager (\#7) }\end{array}$ & Low \\
\hline $\begin{array}{l}\text { Ease of capture of } \\
\text { meaningful } \\
\text { information }\end{array}$ & $\begin{array}{l}\text { 'No the system has not helped with the capture of meaningful } \\
\text { information - not from end user point of view.' Group Accountant } 1 \\
\text { (\#8) } \\
\text { 'The system does not hold meaningful information but data that needs } \\
\text { interpretation for it to become meaningful. A lay person or Head of } \\
\text { Service would not be able to look at a report and assess the true } \\
\text { position of the business.' Group Accountant } 2 \text { (\#9) }\end{array}$ & Low \\
\hline
\end{tabular}


Table 5: Empirical Evidence for Facilitators

\begin{tabular}{|c|c|c|}
\hline $\begin{array}{l}\text { Enabling } \\
\text { Changes }\end{array}$ & Supporting evidence & Rating \\
\hline $\begin{array}{l}\text { Payments and } \\
\text { invoices } \\
\text { matched to } \\
\text { orders (pre- } \\
\text { authorized) }\end{array}$ & $\begin{array}{l}\text { 'For us it's simpler because of the electronic authorization. There is no } \\
\text { coding slip and walking round to get a signature.' Accounts Clerk (\#1) } \\
\text { 'Cuts in paper use and delays in payment. The approval to incur } \\
\text { expenditure is formally evidenced electronically now rather than by } \\
\text { paper based orders and signatures'. AP Supervisor (\#2) }\end{array}$ & Moderate \\
\hline $\begin{array}{l}\text { Mapping and } \\
\text { redesign of } \\
\text { processes }\end{array}$ & $\begin{array}{l}\text { 'We mapped the 'as is' but can't recall mapping the future workflow patterns'. } \\
\text { Group Accountant } 1 \text { (\#8) } \\
\text { 'Not particularly well, workflow reasonably well - it was mapped but } \\
\text { whether all the implications were thought out in terms of man hours, } \\
\text { complications that could arise may not have been taken into account. The } \\
\text { problem was it [process] was mapped as a one for all, Monday to Friday, } \\
9 \text { to } 5 \text { work force, one solution for all and all the other scenario's out of } \\
\text { office hours for other services weren't addressed.' Group Accountant } 2 \text { (\#9) }\end{array}$ & Moderate \\
\hline $\begin{array}{l}\text { Training in } \\
\text { FMS }\end{array}$ & $\begin{array}{l}\text { 'I personally thought the training was fine, training on system setup.' } \\
\text { Budget Manager, (\#4) } \\
\text { 'The initial training was fine but what was lacking was the subsequent } \\
\text { backing to the training that was not available, an on site expert to resolve } \\
\text { day-to-day issues. The weakness the council had was within a few months } \\
\text { of implementation the business systems team who should ensure the } \\
\text { system runs properly became the training support answering operation } \\
\text { queries rather than [having] a dedicated team to answer these [training] } \\
\text { queries. I guess that comes down to cost.' Accounts Clerk (\#1) }\end{array}$ & Moderate \\
\hline $\begin{array}{l}\text { Change in } \\
\text { organizational } \\
\text { culture }\end{array}$ & $\begin{array}{l}\text { 'The Director's email stated that "you will do this". There wasn't a } \\
\text { programme of changing culture.' Group Accountant (\#8). } \\
\text { 'Nothing was done on changing organizational culture'. } \\
\text { '[The Director] sent an email with dates that all orders were going to have } \\
\text { to be done electronically by 1st of April then by 1st August - you will do } \\
\text { this - there wasn't a programme of changing culture.' Principal } \\
\text { Accountant } 2 \text { (\#12) }\end{array}$ & Low \\
\hline $\begin{array}{l}\text { Establish } \\
\text { stable platform } \\
\text { for FMS }\end{array}$ & $\begin{array}{l}\text { 'Time outs and logging back in, backing out, default values, journals } \\
\text { and virements freeze when manually inputting and a single error is made, } \\
\text { have to start again from beginning.' AR Supervisor (\#3) } \\
\text { 'It's constantly slow or going down. There are times when you can't access } \\
\text { it or can't get meaningful estimation of how long the report/query will } \\
\text { take or because it has expired and timed you out and you've got to run it } \\
\text { again.' Group Accountant } 1 \text { (\#8) }\end{array}$ & Low \\
\hline
\end{tabular}


Table 6: Empirical Evidence for Inhibitors

\begin{tabular}{|c|c|c|}
\hline Resistors & Supporting evidence & Rating \\
\hline $\begin{array}{l}\text { Inconsistent } \\
\text { departmental } \\
\text { adoption of } \\
\text { FMS }\end{array}$ & $\begin{array}{l}\text { 'Departments don't work in the same way, some still use paper and } \\
\text { another inputs the information and so there isn't an increase in ease of } \\
\text { capture. Highways for example, go out and carry out their tasks, fill in a } \\
\text { form and that is then used to input into the system.' AR supervisor (\#3) } \\
\text { 'Not all areas place electronic orders within the system and when they } \\
\text { do the outstanding balances on those orders are not house kept promptly } \\
\text { so you never know the true expenditure figure.' AP supervisor (\#2) }\end{array}$ & Moderate \\
\hline $\begin{array}{l}\text { Staff not } \\
\text { engaging with } \\
\text { new ways of } \\
\text { working }\end{array}$ & $\begin{array}{l}\text { 'When we went out and said, throw away your manual order books, as it } \\
\text { now has to be done electronically, we had an uphill struggle to convince } \\
\text { people.' Principal Accountant (\#11) } \\
\text { 'Training was given and people were sent away to make it work in their } \\
\text { area's. They didn't, in my view, embrace it enough to say, "right a whole } \\
\text { new opportunity, a whole new system." I have staff who currently work } \\
\text { in different ways to get the payment onto the system.' AP supervisor (\#2) }\end{array}$ & High \\
\hline $\begin{array}{l}\text { Reports } \\
\text { poorly } \\
\text { designed }\end{array}$ & $\begin{array}{l}\text { 'There were a lot of problems initially around the report side, [...] we } \\
\text { had to run several reports to get the information where this } \\
\text { [information] was available in one previously.' Principal Accountant } 2 \\
\text { (\#12) } \\
\text { 'Formats not easy to read or give to budget managers as the ones you } \\
\text { can give to managers, formatting, stupid colours, not being able to print } \\
\text { on to one page width/depth, you have to play around in Excel.' Business } \\
\text { Systems Accountant (\#5) }\end{array}$ & Moderate \\
\hline $\begin{array}{l}\text { FMS slow } \\
\text { response times }\end{array}$ & $\begin{array}{l}\text { 'The system at times runs unacceptably and frustratingly slow which } \\
\text { maybe another reason why people [ad hoc users] don't what to use it.' } \\
\text { AR Supervisor (\#3) } \\
\text { 'I don't know whether that's the software or hardware but the end } \\
\text { product is slow and frustrating. It might take two minutes to load up a } \\
\text { certain area never mind querying or processing.' Principal Accountant } 2 \\
\text { (\#12) }\end{array}$ & Moderate \\
\hline
\end{tabular}


Table 7: Empirical Evidence for Business Changes from FMS

\begin{tabular}{|c|c|c|}
\hline Business Changes & Supporting evidence & Rating \\
\hline $\begin{array}{l}\text { All orders / } \\
\text { purchasing } \\
\text { documentation to } \\
\text { be approved / } \\
\text { processed } \\
\text { electronically }\end{array}$ & $\begin{array}{l}\text { I think the new way of working in terms of ordering within [the FMS] } \\
\text { and matching the subsequent invoice to the order will over time } \\
\text { generate savings and is part of the new Transactional Services Centre } \\
\text { key role and will actually promote good working practices.' Head of } \\
\text { Finance (\#10) } \\
\text { 'All paper order books have been collected which people were } \\
\text { reluctant to return. All ordering is done in the department having the } \\
\text { goods/services, invoices come with the order number and information } \\
\text { for the supplier is pulled in [from the FMS].' Business Systems } \\
\text { Manager, (\#7) }\end{array}$ & Moderate \\
\hline $\begin{array}{l}\text { Changes in the } \\
\text { role of } \\
\text { accountants and } \\
\text { budget managers } \\
\text { to more value } \\
\text { adding activities }\end{array}$ & $\begin{array}{l}\text { 'Budget managers are meant to review it but historically they haven't } \\
\text { done it unless they have been forced to do it which is where we are } \\
\text { going with it now.' Strategic Director of Resources (\#13) } \\
\text { 'There isn't dramatic change but it is the human intervention, people } \\
\text { not doing things that is lacking rather than the system.' Business } \\
\text { Systems Accountant (\#5) }\end{array}$ & Low \\
\hline
\end{tabular}


Figure 1: Research Framework

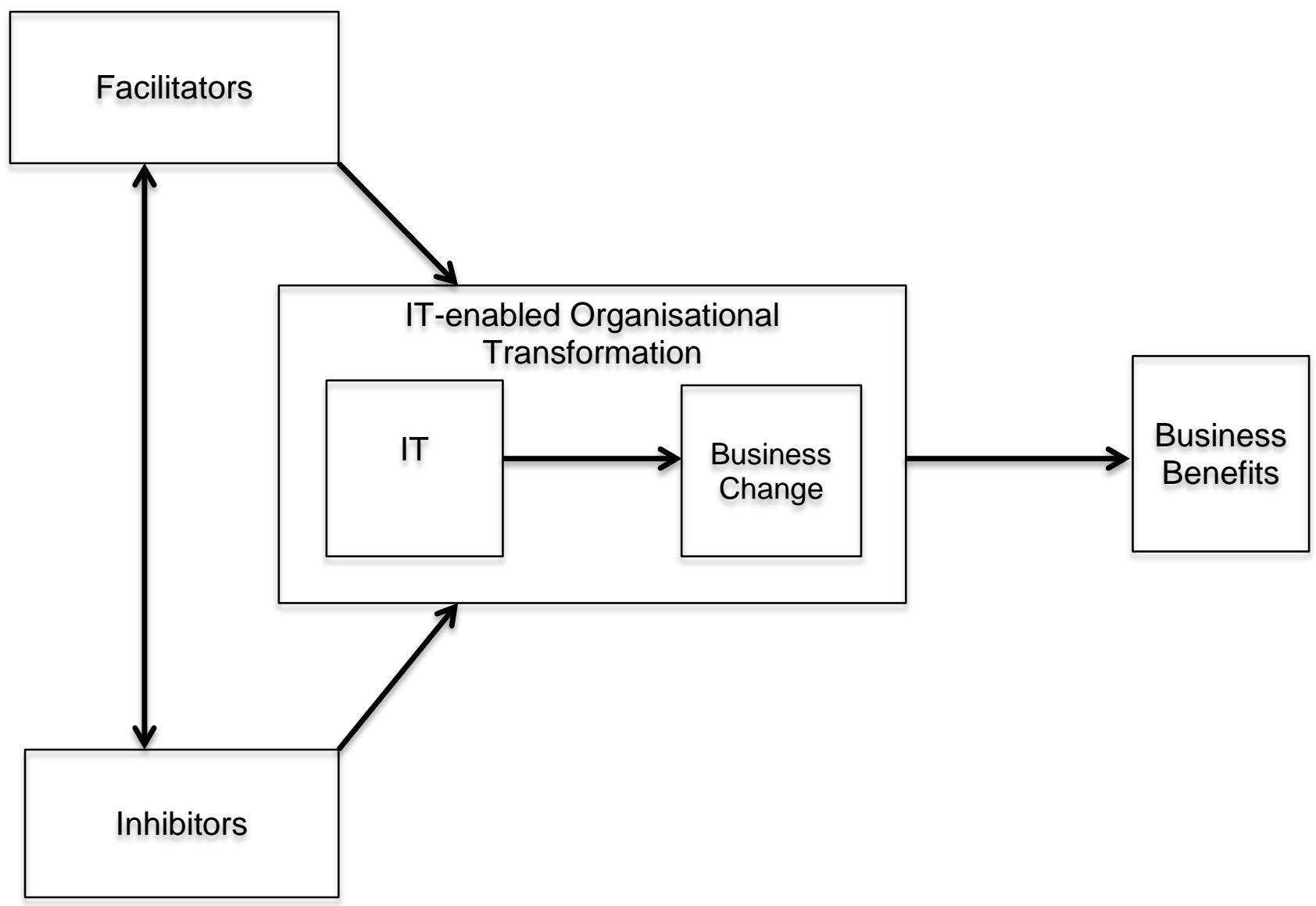


Figure 2: Extended Benefits Dependency Network for FMS (Ward et al. 1996)

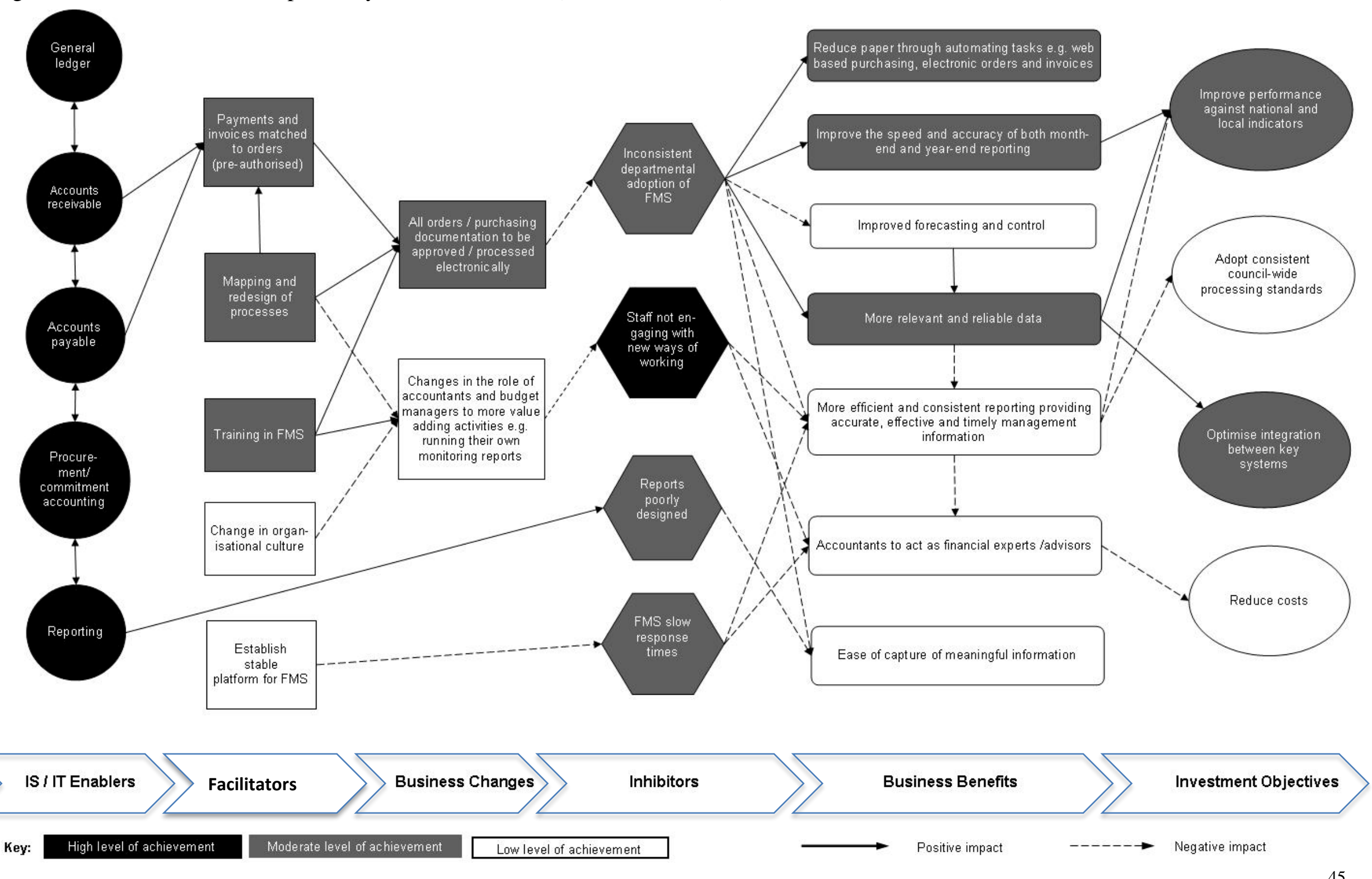

